\title{
BMJ Open How do community health committees contribute to capacity building for maternal and child health? A realist evaluation protocol
}

\author{
Brynne Gilmore, ${ }^{1}$ Eilish McAuliffe, ${ }^{2}$ Fiona Larkan, ${ }^{1}$ Magnus Conteh, ${ }^{3}$ \\ Nicola Dunne, ${ }^{3}$ Michele Gaudrault, ${ }^{4}$ Henry Mollel, ${ }^{5}$ Nazarius Mbona Tumwesigye, ${ }^{6}$ \\ Frédérique Vallières ${ }^{1,7}$
}

To cite: Gilmore B,

McAuliffe E, Larkan F, et al. How do community health committees contribute to capacity building for maternal and child health? A realist evaluation protocol. BMJ Open 2016;6:e011885. doi:10.1136/bmjopen-2016011885

- Prepublication history and additional material is available. To view please visit the journal (http://dx.doi.org/ 10.1136/bmjopen-2016011885).

Received 11 March 2016 Revised 29 July 2016 Accepted 29 July 2016

CrossMark

For numbered affiliations see end of article.

Correspondence to

Brynne Gilmore;

gilmorb@tcd.ie

\section{ABSTRACT}

Introduction: The proposed research is part of ongoing operations research within World Vision's Access: Infant and Maternal Health Programme. This study aims to identify key context features and underlying mechanisms through which community health committees build community capacity within the field of maternal and child health. This may help to improve programme implementation by providing contextually informed and explanatory findings for how community health committees work, what works best and for whom do they work for best for. Though frequently used within health programmes, little research is carried out on such committees' contribution to capacity building -a frequent goal or proposed outcome of these groups.

Methods and analysis: The scarce information that does exist often fails to explain "how, why, and for whom' these committees work best. Since such groups typically operate within or as components of complex health interventions, they require a systems thinking approach and design, and thus so too does their evaluation. Using a mixed methods realist evaluation with intraprogramme case studies, this protocol details a proposed study on community health committees in rural Tanzania and Uganda to better understand underlying mechanisms through which these groups work (or do not) to build community capacity for maternal and child health. This research protocol follows the realist evaluation methodology of eliciting initial programme theories, to inform the field study design, which are detailed within. Thus far, the methodology of a realist evaluation has been well suited to the study of community health committees within these contexts. Implications for its use within these contexts are discussed within.

Ethics and dissemination: Institutional Review Boards and the appropriate research clearance bodies within Ireland, Uganda and Tanzania have approved this study. Planned dissemination activities include via academic and programme channels, as well as feedback to the communities in which this work occurs.

\section{Strengths and limitations of this study}

- Though frequently used within health promotion activities in low-income settings, there is a dearth of evidence on community health committees and how they work to build capacity for health.

- Evidence that does exist on community health committees often fails to take a systems-thinking approach to the evaluation of such committees and neglects the contextual factors and human conditions that influence programme functioning.

- As realist evaluations work to explain what works best, for whom and why, this research has the potential to provide more contextually relevant and person-centred recommendations for increasing efficiency and effectiveness of community health committees for maternal and child health.

- Difficulties and limitations with this chosen methodology may arise, however, as there has been little research using realist evaluations in low-income countries and therefore limited precedent to follow.

\section{INTRODUCTION}

As set out in The Ottawa Charter for Health Promotion 1986, ${ }^{1}$ strengthening community actions by enhancing and working towards the empowerment of communities to improve ownership of and control their own health actions is an essential part of health promotion and health systems strengthening. Consequently, many governments and/or organisations have taken to introducing community groups that work together to achieve a specific health goal, and promote community participation for health, advocacy and raising awareness. ${ }^{2}$ These community groups are referred to in a number of different ways throughout the literature including, but not 
limited to, committees, coalitions, networks, associations and partnerships.

The study presented examines a community health committee or coalition, as defined by Fieghery and Rogers (1990) as 'community coalitions', or “...a group of individuals representing diverse organisations, factions, or constituencies within the community who agree to work together to achieve a common goal" (ref. 3. pg. 1 ), and adds that they are situated at the community level as opposed to health facility level. Community coalitions are often considered to have a more sustainable influence on community health and well-being, in part due to the collaboration between professionals and community (grassroots) members and since they respond to identified problems by employing a shared socioecological lens which addresses the multiple determinants of community health and well-being. ${ }^{4}$ Additionally, coalitions can create more harmonisation of health initiatives, increase potential for community empowerment and facilitate the participation of community members in health initiatives-all with a view to increasing programme ownership and sustainability. ${ }^{5}$ It is noted that the collaborative nature and interorganisational relationship focus of coalitions offers effective solutions to low resource capacity by distributing responsibility among its members, increasing available resources and creating partnerships with other vested groups. ${ }^{6}$ To this end, they are predicted to achieve a more significant health result than any entity could achieve individually due to resource sharing, networking and collaboration and systems thinking approaches, ${ }^{5}$ while also allowing for the potential of increased sustainability to do ownership sharing.

Often noted as a consequence of such collaborations, and sometimes as an objective in and of itself, community coalitions are strategically positioned for community capacity building. As defined by Labonthe and Laverack and used throughout this study, community capacity building is the 'increase in community groups' abilities to define, assess, analyse and act on health... concerns of importance to their members'(ref. 7. pp. 114). However, while the conceptual and theoretical foundations of such coalitions within high-income countries are well defined, the development and testing of these theories in relation to practice are largely missing from past and current literature. ${ }^{5}$ Though the majority of literature from high-income countries (HICs) refers to such groups as coalitions this paper uses the term community health committee (CHC), a presumed synonym more consistent with terminology from low-income countries (LICs) and our case studies.

While heavily advocated for and used in maternal and child health programmes, research gaps exist around how to better strengthen and implement CHCs and their relationships with community health workers, ${ }^{8}$ and on what specific features of community health committees are most effective in the promotion of maternal and child health. Though more recent reports have demonstrated the ability of community health committees to positively contribute to health outcomes in sub-Saharan Africa, there remains a dearth of evidence on how exactly such committees work and what features contribute to community capacity building. ${ }^{9}{ }^{10}$ In this same vein, there is a dearth of information specifically on CHCs and their use within LICs. As a result, knowledge of CHC for health in low-income settings is often conjectured from other community structures (eg, health facility committees) or from community coalition literature from HICs, specifically North America where there exists a larger body of evidence on community coalitions.

The context in which CHCs (or coalitions) are implemented is recognised as a key determinant to their success. Butterfoss, Goodman and Wandersman (1993) note that contextual factors contribute to the success or failure of coalitions and their activities within North America. ${ }^{6}{ }^{11}$ Similarly, a recent study examining village safe motherhood committees in Guinea ${ }^{12}$ acknowledged that evidence for how change is being catalysed from these groups at the community level is lacking. The authors state that findings "confirm the need for-and feasibility of-evaluation frameworks that go beyond traditional intervention/comparison designs to assess the influence of contextual factors and intervention exposure" (pg. 8). Taken together, the increasing use of CHC programmes in low-income countries and the acknowledgement that context plays an important role in the successful implementation of CHC programmes, points to a need to correct the current evidence imbalance by conducting more research among CHCs in lowincome contexts.

The methodology of a realist evaluation appears particularly relevant to the study of community health committees for several reasons. First, CHCs are complex health interventions; they work in line with socioecological models, which understand that programmes operate in open systems with multiple factors interacting at different levels, producing both intended and unintended outcomes. ${ }^{5} 13{ }^{14}$ Second, there is a need for methodologies studying CHCs to be reflective of their operation in open systems, and to include a strong theoretical component. ${ }^{15-19}$ Third, while previous studies have identified important contextual factors for their operationalisation, ${ }^{20}$ an explanation on how these groups work, who they work best for and why is still missing from this field. Finally, realist evaluations are increasingly being used to inform complex health interventions, ${ }^{21-23}$ with an emerging application in lowincome and middle-income countries. ${ }^{23-29}$ Advocates note that their methodological design better enables the evaluation of complex health interventions compared to quasi-experimental designs. ${ }^{22} 30$

\section{Realist evaluations}

A form of theory-based evaluation, realist evaluations aim to identify "what works, for whom, and under what 
circumstances', by developing context-mechanismoutcome configurations (CMOCs). ${ }^{31}$ These configurations describe how specific contextual factors (C) work to produce particular mechanisms $(\mathrm{M})$, and how this combination generates outcomes $(\mathrm{O})$ in programmes. A realist evaluation aims to uncover these generative mechanisms that may explain how outcomes occur by exploring the particular patterns of $\mathrm{C}$ and $\mathrm{M}$ interactions. As such, part of their objective is to uncover these theories (implicit and underlying) that describe the explanatory pathway of how change occurs. Dubbed a programme theory, these theories are refined through case studies which work to understand the mechanisms, unpacking the 'black box' between intervention and outcome. $^{28}$ The goal is to produce a more refined middle range theory (MRT) of how the programme works by identifying regular patterns within reality. The MRT, defined as the "theory that lies between the minor but necessary working hypotheses... and the all-inclusive systematic efforts to develop a unified theory that will explain all the observed uniformities of social behaviour, social organisation and social change" (ref. 32. pg. 39), is therefore a result of programme specification. Figure 1, adapted from Van Belle et al $2010,{ }^{28}$ provides an example tailored to this intervention.

As outlined in figure 2 (adapted from Pawson and Tilley $(1997)^{31}$ and Marchal et $a l,{ }^{22}$ ) the cycle of research for a realist evaluation largely follows typical evaluation cycles of developing (eliciting) a hypothesis (theory), and testing (refining) this through empirical studies. The hypothesis/theory informs the data collection and methods used throughout the study, those that are best suited to test it. In this step, the researcher is assigned with hypothesising the mechanisms that may operate, and the contexts in which they might operate, to produce outcomes of the intervention, which are then refined through case studies.

\section{Aims, objectives and research questions}

Aim

The aim of this study is to identify key context features and underlying mechanisms through which community health committees (CHCs) build community capacity within the field of maternal and child health.

\section{Research question}

How does context shape the mechanisms through which community health committees contribute to capacity building for maternal and child health, and why?

\section{Objectives}

- To develop an initial programme theory (IPT) of how CHCs work to build community capacity

- To investigate and identify outcomes of CHCs and to describe how the CHCs work, for whom and why?

- To refine the IPTs based on a series of case studies to identify a theory that is of middle range for how CHCs work to build capacity for MCH

\section{Eliciting of IPTs}

As programmes are theories incarnate, an essential step in conducting a realist evaluation is to make explicit such theories, followed by mapping and selecting the theories to be studied. ${ }^{31}$ For the proposed study, following realist evaluation techniques, ${ }^{31}$ an IPT was elicited through the following stages: (1) Literature on community committees (coalitions), health promotion and health volunteers was reviewed as well as intervention programme documentation (guidelines and training manuals). These documents were analysed using a realist lens and worked to identify CMOCs. The emerging theories (see online supplementary file 1 for data sources) were of a high level of abstraction, and therefore step (2) worked to bring more specification to the theories by incorporating programme architects' and implementers' theories through key informant interviews using realist techniques. The interview questions were designed using the previously identified CMOCs for further refinement, to understand the actual programme implementation (compared to documented) and to further explore the contextual elements required for implementation. A further round of analysis occurred using the $\mathrm{CMO}$ configuration as an analytical tool.
Figure 1 Outcome process model for AIM-Health (adapted from Van Belle et al 2010). AIM-Health, Access Infant and Maternal Health.
Actual Intervention (AIM-Health's COMMs)

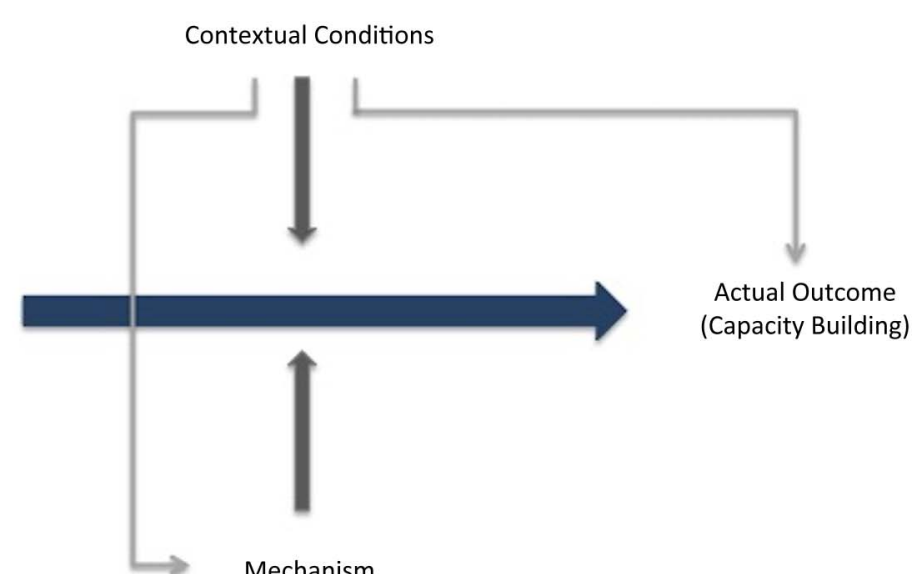




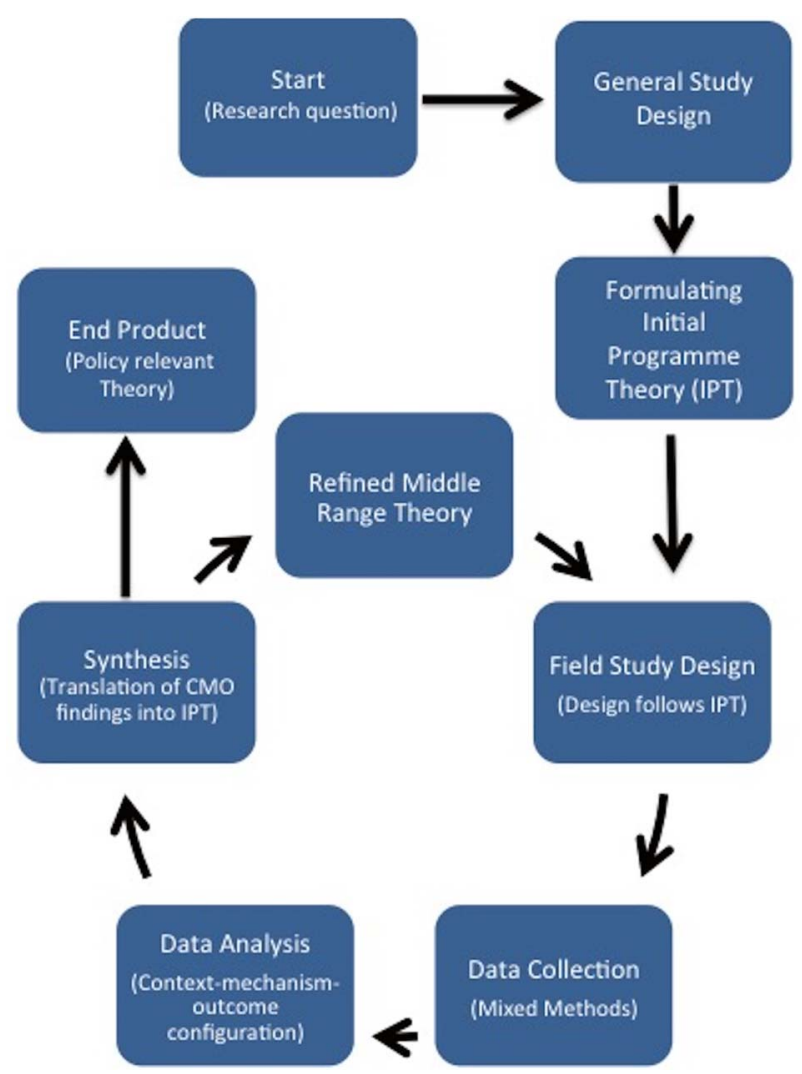

Figure 2 Realist evaluation cycle.

Findings from the initial analysis are presented in terms of contexts, mechanisms and outcomes and the formulated CMOCs, presented in table 1. In summary, we identified three main levels important for community health committee functioning, which worked to guide our CMO identification: individual, group and community (all of which are situated within the wider socioecological lens). Within each level, possible CMOCs were identified that work to explain how CHCs best work to promote community capacity building.

Step 3 consisted of the mapping and selection of the most appropriate theories to refine throughout the course of the study, which is presented via a visual representation in figure 3. These were then used to design our study protocol for further refinement and specification, where the most appropriate methods and tools were selected for its refinement, as detailed in the following section.

\section{METHODS}

\section{General study design}

Two case studies using the same complex health intervention involving community health committees were purposefully selected to best test and refine the IPT. The specific sites were chosen for two main reasons: First, by using case studies set across different contexts with the same programme design, individual programme theory refinement across the sites and the subsequent comparison between sites may work to identify theories that are of middle range for CHCs building community capacity; and second, specifically concerning the sites, reports from programme managers indicate that the two programmes are achieving different levels of their intervention aim of capacity building. Having contrasting perceived effectiveness may provide additional insight into 'what works, for whom and why' for community health committees.

\section{Intervention}

Each study will be conducted within World Vision's Area Development Programmes (ADPs) implementing the AIM-Health Programme. A complex health intervention, World Vision Ireland's AIM-Health programme works across 10 contexts in 5 sub-Saharan African countries (Kenya, Uganda, Tanzania, Sierra Leone and Mauritania) to reduce maternal and child mortality and morbidities by enhancing the health knowledge of women and households, and by increasing capacity within communities to respond to its citizens' health needs. Using what World Vision titles the 7-11 Strategy, AIM-Health engages community health workers (CHWs) to deliver a number of timed and targeted counselling (ttC) to women and households at specific intervals throughout their pregnancy and throughout the first 2 years of a child's life. These messages - 7 for women and 11 for children under 2 years-were developed from cost-effective, evidence-based interventions delivered in the community. ${ }^{33-35}$ Using a multifaceted approach, the 7-11 Strategy works by targeting individuals, communities and their environment through CHWs, community health committees (which World Vision titles COMMs) and citizen voice in action networks and Positive Deviance (PD) Hearth interventions, respectively.

Serving as a link between the community and more formal health services, COMMs are a health-focused community group that coordinates and manages health activities and civil society strengthening. Within the World Vision model, these committees are ideally initiated by the Ministry of Health in their respective countries, and jointly trained by World Vision on the 7-11 ttC strategy and other AIM-Health activities. The main duties of COMMs include: providing a support system for community health workers and other community health volunteers, assessing and tracking the community health situation, mobilising the community for improved health, responding to barriers to healthrelated behaviour change at the community level, assisting with communication with and from the health system and local administration and advocating around issues leading to improved health systems. ${ }^{36}$ The establishment and operationalisation of these groups is a prerequisite for any 7-11 Strategy implementation. World Vision's COMMS are equivalent to community health committees (coalitions) in description and function, and are therefore referred to and treated as such.

Both study sites initiated the COMM programme in mid-2014, several years after the start of the AIM-Health 


\begin{tabular}{|c|c|c|c|c|}
\hline $\begin{array}{l}\text { Level/ } \\
\text { potential } \\
\text { elements }\end{array}$ & Contexts+ & Mechanisms= & Outcomes & Potential explanatory CMOCs \\
\hline $\begin{array}{l}\text { Individuals in } \\
\text { committee }\end{array}$ & $\begin{array}{l}\text { Attributes: age, gender, time } \\
\text { and availability for group, } \\
\text { experience and education in } \\
\text { health (MCH) } \\
\text { Previous engagement with } \\
\text { community (respect) } \\
\text { Incentives (financial and } \\
\text { non-financial) }\end{array}$ & $\begin{array}{l}\text { Volunteerism and } \\
\text { self-actualisation } \\
\text { Commitment of members to } \\
\text { community and committee } \\
\text { Motivation (intrinsic and } \\
\text { extrinsic) }\end{array}$ & $\begin{array}{l}\text { Community recognition/ } \\
\text { respect } \\
\text { Decreased workload for some } \\
\text { members (increased sharing } \\
\text { of resources) } \\
\text { Potential for career } \\
\text { advancement } \\
\text { Increased collaboration } \\
\text { between committee members }\end{array}$ & $\begin{array}{l}\text { Individuals within the } \mathrm{CHC} \text { are likely to provide } \\
\text { supportive and consistent engagement for } \\
\text { activities if they have strong motivation, a desire } \\
\text { for volunteering for their community, and are } \\
\text { committed to the group and its objectives. This } \\
\text { may be influenced by the individual members' } \\
\text { specific attributes (such as availability of time and } \\
\text { knowledge), previous experience and incentives } \\
\text { provided to them. This results in a decreased } \\
\text { workload for the committee, due to increased } \\
\text { collaboration, increased respect by community } \\
\text { members and an overall committed committee } \\
\text { better able to initiate activities and work towards } \\
\text { building community capacity. }\end{array}$ \\
\hline Committee & $\begin{array}{l}\text { Membership make-up, } \\
\text { operation and processes, } \\
\text { leadership } \\
\text { Relationship to other } \\
\text { stakeholders (pressure from } \\
\text { hierarchy) } \\
\text { Sustained support: resources, } \\
\text { training and supervision }\end{array}$ & $\begin{array}{l}\text { Buy-in from relevant } \\
\text { stakeholders (NGO and } \\
\text { MoH) } \\
\text { Respect of community } \\
\text { members } \\
\text { Harmonisation of activities } \\
\text { between initiatives } \\
\text { Shared resources and } \\
\text { knowledge for programme } \\
\text { Communication and } \\
\text { trustworthiness between } \\
\text { members and stakeholders }\end{array}$ & $\begin{array}{l}\text { Service delivery: increasing } \\
\text { services for population; } \\
\text { initiation of new activities for } \\
\text { MCH } \\
\text { Group synergy } \\
\text { Implementation of activities at } \\
\text { multiple levels of society } \\
\text { Strong programme } \\
\text { management }\end{array}$ & $\begin{array}{l}\text { Committees that have broad membership } \\
\text { make-up have strong operations and processes } \\
\text { in place, have strong leadership with consistent } \\
\text { training and supervision and work to build } \\
\text { relationships with other community stakeholders } \\
\text { are more likely to have buy-in from other invested } \\
\text { parties, gain the respect of community members, } \\
\text { align health activities from different activities for } \\
\text { more harmonised services, share resources and } \\
\text { knowledge, and have strong communication and } \\
\text { trust between members. This collaboration works } \\
\text { to increase service delivery, with implementation } \\
\text { addressing multiple levels of society, and also } \\
\text { works to provide committee synergy and a } \\
\text { strengthening of programme management, all of } \\
\text { which are assumed to contribute capacity } \\
\text { building for } \mathrm{MCH} \text {. }\end{array}$ \\
\hline
\end{tabular}




\begin{tabular}{|c|c|c|c|c|}
\hline $\begin{array}{l}\text { Level/ } \\
\text { potential } \\
\text { elements }\end{array}$ & Contexts+ & Mechanisms= & Outcomes & Potential explanatory CMOCs \\
\hline Community & $\begin{array}{l}\text { Past experience with } \\
\text { committees and other } \\
\text { initiatives: community } \\
\text { receptiveness } \\
\text { - Availability and strength of } \\
\text { health services and system for } \\
\mathrm{MCH} \\
\text { Health policies and priorities } \\
\text { of system }\end{array}$ & $\begin{array}{l}\text { Community Organisation, } \\
\text { Mobilisation and } \\
\text { Participation } \\
\text { Community member's } \\
\text { ability to participate } \\
\text { Increasing advocacy skills } \\
\text { for } \mathrm{MCH} \\
\text { Community critical } \\
\text { awareness }\end{array}$ & $\begin{array}{l}\text { Development of local } \\
\text { leadership for health } \\
\text { Community needs } \\
\text { assessments and evaluations } \\
\text { Increase in health services for } \\
\text { MCH } \\
\text { Increase in health system } \\
\text { responsiveness } \\
\text { Decrease of workload for } \\
\text { health staff and other } \\
\text { volunteers }\end{array}$ & $\begin{array}{l}\text { Committees that operate in communities with } \\
\text { positive past experiences with similar initiatives, } \\
\text { that have existing } \mathrm{MCH} \text { health services and } \\
\text { strong systems to support their implementation, } \\
\text { and policies that favour their implementation, are } \\
\text { assumed to lead to increased community } \\
\text { organisation, mobilisation and participation for } \\
\text { maternal and child health. They are also } \\
\text { assumed to increase community members' ability } \\
\text { to participate in health activities, have critical } \\
\text { awareness of their rights, and advocate for their } \\
\text { health needs. This is assumed to result in } \\
\text { creating local leadership (champions) for MCH, } \\
\text { increase evaluation and needs assessment, } \\
\text { increase health services and health } \\
\text { responsiveness, and decrease the workload for } \\
\text { health staff and volunteers. }\end{array}$ \\
\hline Wider context & \multicolumn{3}{|c|}{$\begin{array}{l}\text { Socioecological environment: conducive policies with government backing supporting committee } \\
\text { structures and objectives, in line with community and NGO objectives; organisational structures } \\
\text { around } \mathrm{MCH} \text { health programming from government and NGO level }\end{array}$} & $\begin{array}{l}\text { Committees that are able to strengthen the three } \\
\text { aforementioned levels of functioning (individual, } \\
\text { committee and community), in line with } \\
\text { pre-existing socioecological contextual factors, } \\
\text { are assumed to promote community capacity } \\
\text { building for maternal and child health. }\end{array}$ \\
\hline
\end{tabular}




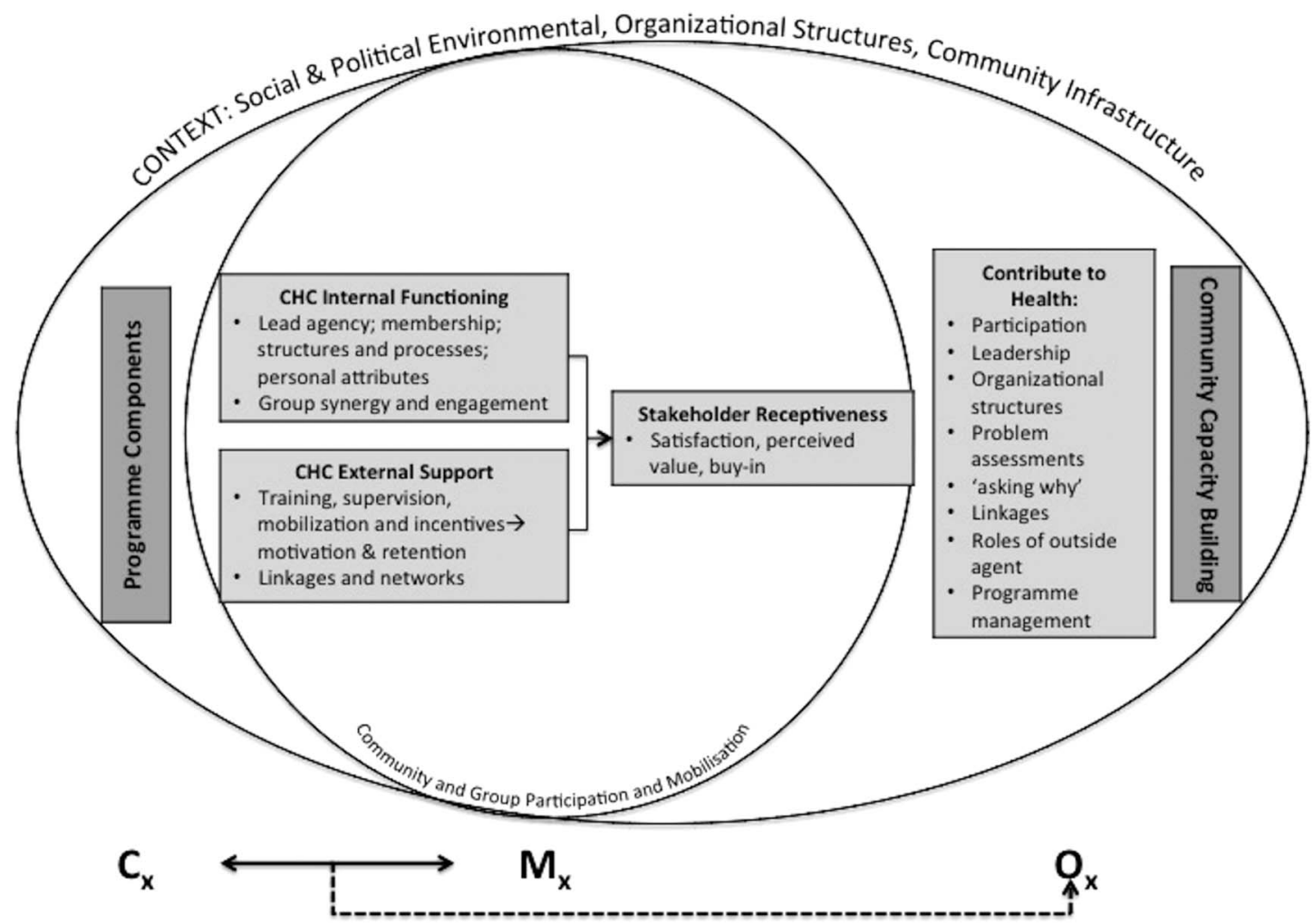

Figure 3 Initial programme theory of $\mathrm{CHCs}$ for $\mathrm{MCH}$ community capacity building. $\mathrm{CHC}$, community health committee; $\mathrm{MCH}$, maternal and child health.

Table 2 Key Demographic Health Survey (DHS) MCH indicators for study sites

\begin{tabular}{lll}
\hline Indicator & Uganda 2011 DHS $^{\star 57}$ (\%) & Tanzania 2010 DHSt $^{\mathbf{5 8}}(\%)$ \\
\hline Delivery by skilled provider & 41 & 46 \\
Postnatal care for mother within 2 days delivery & 21 & 44 \\
$12-23$ months fully vaccinated & 62 & 77 \\
$<60$ months with diarrhoea in the past two weeks & 14 & 22 \\
Care seeking for diarrhoea in the past two weeks & 52 & $53 \ddagger$ \\
$<60$ months stunted & 42 & 56 \\
\hline
\end{tabular}

${ }^{*}$ For the southwest region of Uganda.

†For the Dodoma region of Tanzania.

FFor the Central region.

$\mathrm{MCH}$, maternal and child health.

Programme. Programme managers in the sites have indicated that each parish has trained a COMM group. Though their actual membership make-up, organisational structures, training and support will most likely vary between contexts, guidelines suggest that membership should include 8-12 individuals selected by the community that represent diverse backgrounds and interests. It is suggested that members include: youth, religious leaders, community leadership and representatives, as well as a community health worker, a local health staff member and a minimum three females, one with a COMM leadership role (chair, cochair or secretary).

\section{Setting}

The specifically selected sites for this research will occur in rural areas of two East African countries: North
Rukiga, in the Kabale District of Southwestern Uganda and Mundemu, in the Bahi District of the Dodoma Region in central Tanzania. Table 2 presents key maternal and child health indicators for both sites. The accompanying figures highlight the need for strong child health programmes, and highlight some of the contextual similarities between the two sites.

Case Study 1, North Rukiga, Uganda: North Rukiga is located in Rukiga county, one of four counties in the Kabale district of Southwestern Uganda. North Rukiga comprises two subcounties, Kashambya and Rwamucucu, totalling 13 parishes and 162 villages with $\sim 52500$ residents. ${ }^{37}$ It was reported in 2010 that over $15 \%$ and $48 \%$ of Kabale's population was under the age of 5 and 14 years, respectively. ${ }^{37}$

Background Case Study 2, Bahi, Tanzania: Bahi district is one of the six districts in the Dodoma region and 
comprises around $13 \%$ of the Dodoma land region. ${ }^{38}$ Bahi has 4 divisions, 20 wards and 56 villages, with Mundemu being among one of the administrative wards. ${ }^{38}$ According to 2013 figures, Bahi District's population has $18 \%$ of citizens under the age of 5 years, and $\sim 48 \%$ under the age of $14 .^{39}$

\section{Field study design}

Following the development of the realist evaluation framework, the methods for this study were informed by the above IPT and research questions and purposefully selected to best fit the refinement of the theory. This research is planned to occur from November 2015 to June 2016. The proposed study consists of focus group discussions, in-depth interviews, observations and surveys administered to stakeholders involved in community health committees. Table 3 details the proposed data collection methods and tools of the field study.

\section{Data collection}

As detailed in table 3, this study employs a mix of qualitative and quantitative data tools including focus group discussions, in-depth interviews, key-informant interviews, document reviews and surveys. Qualitative methods will be used to explore and refine the theory collaboratively with research participants. Key informant interviews are used to collect specialist knowledge ${ }^{40}$ and within this study be done with Ministry of Health and NGO stakeholders, specifically to test the theory in regard to context (programme inputs), outcomes and mechanisms of external support and at the level of the community and society. The committees' in-depth interviews and other stakeholder focus groups will be used to detail individuals' views and interpretations of the intervention, ${ }^{41}$ and to explore the specific theories, ${ }^{42}$ in addition to contextual information and outcomes. Specifically, CHCs will be interviewed to refine mechanisms relating to the internal functioning and individual characteristics of the members, while also supplementing the survey information. Community members will be interviewed with the goal of refining theories relating to community responsiveness, context and committee outcomes.

Quantitatively, the Coalition Self-Assessment Scale ${ }^{43}$ will be administered to all $\mathrm{CHC}$ members to explore the Community Coalition Action Theory (CCAT), ${ }^{44-47}$ and the internal workings of the group. Aligned with CCAT, the CSAS explores the experiences and perceptions of coalition members and group processes. The purpose of this is to examine theories regarding the internal workings of the CHC, specifically relating to membership, structures and processes, leadership, trustworthiness and communication, group synergy and engagement, as well as perceived outcomes of the CHC as reported by the

Table 3 Data collection and tools

\begin{tabular}{|c|c|c|c|}
\hline $\begin{array}{l}\text { Concept/theory to be } \\
\text { explored }\end{array}$ & Proposed methods & Main stakeholder group and number* & Total totals \\
\hline \multirow[t]{2}{*}{ Intervention inputs } & Document analysis & MoH, World Vision Records & NA \\
\hline & Key informant interviews & Programme managers, $\mathrm{MoH}$ manager $(n=5)$ & 5 \\
\hline \multirow[t]{4}{*}{$\begin{array}{l}\text { Community coalition } \\
\text { action theory }\end{array}$} & $\begin{array}{l}\text { Coalition Self- } \\
\text { Assessment Survey } \\
\text { (CSAS) }\end{array}$ & Delivered to all $\mathrm{CHC}$ members $(n=10)$ & 10 \\
\hline & In-depth interviews & $\mathrm{CHC}$ members ( $\mathrm{n}=4$ per group) & 4 \\
\hline & Observations & $\mathrm{CHC}$ group meetings & NA \\
\hline & Document review & $\mathrm{CHC}$ meeting minutes, $\mathrm{WV}$ and $\mathrm{MoH}$ documentation & NA \\
\hline \multirow[t]{3}{*}{ External support } & In-depth interviews & $\mathrm{CHC}$ members ( $n=5$ per group) & 5 \\
\hline & Focus group discussions & Community health workers ( $n=1$ group, with $6-8$ people) & $6-8$ \\
\hline & Key informant Interviews & Programme managers, $\mathrm{MoH}$ manager $(n=4)$ & 4 \\
\hline \multirow{2}{*}{$\begin{array}{l}\text { Community } \\
\text { responsiveness }\end{array}$} & Focus group discussions & Community health workers ( $n=1$ group, with $6-8$ people) & $6-8$ \\
\hline & Focus group discussions & $\begin{array}{l}\text { Male and female community members ( } n=2 \text {, with } 6-8 \\
\text { people per group) }\end{array}$ & $6-8$ \\
\hline \multirow{6}{*}{$\begin{array}{l}\text { Capacity building and } \\
\text { other outcomes }\end{array}$} & In-depth interviews & $\mathrm{CHC}$ members ( $\mathrm{n}=5$ per group) & 5 \\
\hline & Focus group discussions & $\begin{array}{l}\text { Community Health Workers ( } n=1 \text { group, with } 6-8 \\
\text { people) }\end{array}$ & $6-8$ \\
\hline & Focus group discussions & $\begin{array}{l}\text { Male and female community members ( } n=2 \text {, with } 6-8 \\
\text { people per group) }\end{array}$ & $6-8$ \\
\hline & Key informant interviews & Programme managers, $\mathrm{MoH}$ manager $(n=5)$ & 5 \\
\hline & $\begin{array}{l}\text { Domains of capacity } \\
\text { survey }\end{array}$ & Administered to all participants $(n=40)$ & 40 \\
\hline & Document review & $\mathrm{MoH}, \mathrm{WV}$ and $\mathrm{CHC}$ documentation & NA \\
\hline \multicolumn{3}{|c|}{ Total estimated number of participants in each case study } & 40 \\
\hline
\end{tabular}


members. The CSAS has been used in several studies of community coalitions ${ }^{48} 49$ and has been recommended based on high face validity and its in-depth nature. ${ }^{50}$ To further explore the elicited outcome of community capacity building, this research will use Laverack's nine domains: participation, leadership, organisational structures, problem assessment, resource mobilisation, 'asking why', links with others, role of outside agents and programme management. ${ }^{51}{ }^{52}$ Observational data and programme documents, including group meeting minutes and Ministry of Health (MoH) and NGO reports, will also be collected to provide further insight specifically into the context and outcomes of the CHCs.

\section{Realist data collection}

For qualitative methods, data collection will be performed using realist interview techniques, akin to the 'teacher-learner technique'. This involves the researcher teaching their programme theories to the participant who then provides their own theory for collaborative conceptual refinement. ${ }^{31}$ Important to note is the iterative and ongoing nature of realist evaluation data collection, and as such the numbers given are only approximate since, as highlighted by Manzano, the "process of theory-testing is unpredictable, unstable and uncertain" (ref. 53. pg. 7). Using an iterative process by reinterviewing participants and later stages allows one's understanding of the programme and process to be further refined as the researcher most likely has developed theories and become more knowledgeable on the programme. ${ }^{53}$ Revisiting participants for subsequent interviews has been built into the data collection schedule though details on what and who will be involved will be decided on after theory refinement has occurred.

Data collection from case studies in site 1 (Uganda) will be collected and analysed prior to data collection within case studies in site 2 (Tanzania). As indicated in figure 2, the field study and data collection design of the second case study may change depending on the refined theory from the first case study.

\section{Sampling}

Convenience sampling will be conducted at the level of the CHC, with potential participants identified by World Vision. Two CHCs from each location will be sampled and considered as separate case studies. Once all CHC members have been identified, all other participants (CHWs, community members), bar key informants, will be sampled from the CHC's catchment area. Since all willing CHC members will be surveyed with the CSAS, a sampling strategy for this group is not required. All participants for qualitative interviews will be purposefully sampled depending on their inclusion criteria For CHWs, this includes: trained in the 7-11 Strategy; working from the same health centre as the CHCs; and providing informed consent. For community members, the inclusion criteria is: being a potential beneficiary of the 7-11 Strategy; being within the CHC's catchment area; and providing informed consent. Key informants will be chosen based on their interaction with the CHCs (eg, nurse from the same health unit and programme managers) and must provide informed consent. All participants will be administered the capacity assessment.

\section{Analysis and synthesis}

Quantitative data will be used descriptively to inform mechanism development and analysed in Excel (V.14). Qualitative data, including documentation and interviews, will be analysed in NVivo for Mac (V.11). This study will use the CMOC as an analytical tool for the analysis. As highlighted by several authors, ${ }^{21} 225455$ there is little guidance on the specific analysis approach to use in a realist evaluation. While some propose analytical induction, ${ }^{21}$ or thematic analysis, ${ }^{56}$ others such as Westhorp ${ }^{54}$ and Kazi ${ }^{17}$ have developed specific analysis techniques 'realist qualitative analysis' and the study of 'enabling, disabling and generating mechanisms', respectively.

This study proposes to use CMOCs as a guide and analytic tool, with the qualitative data undergoing rounds of thematic analysis. Preliminary codes will be developed from themes in the IPT for the first round of qualitative coding. Subsequent rounds of coding will deduce more specific themes and work to generate CMOCs. Once this has occurred, findings will be compared to the IPT, and will work to refine the theories to best reflect the emerging findings.

\section{Dissemination}

All participants will be required to provide written informed consent prior to data collection, unless they are unable to do so (eg, those who are illiterate), in which case verbal consent will be taken in addition to a thumbprint. This process includes the distribution of study materials a minimum of 7 days prior to planned collection for participant consideration. Study introduction and information including: study procedure, risks, benefits, right to withdrawal, provisions of confidentiality and potential for publication will all be explained with participants signing consent forms to this extent. All documents will be prepared in English and the local language (Rukiga in Uganda and Kiswahili in Tanzania). Except for consent forms, which will be kept in a separate locked location, all documents will use a participant number to maintain confidentiality.

Dissemination will take place through academic and programme channels, via open access publications or presentations, and research/policy reports for AIM-Health stakeholders and participants, respectively. Researchers will be available during and after the research to work with implementing partners on translating findings into practice. Specifically for participants, policy briefs with contact information will be made available in the research language (Rukiga or Swahili) and distributed at the committees' meeting place and/or nearest health facility. Additionally, dissemination 
meetings with $\mathrm{MoH}$ and NGO staff in the respective research countries have been planned.

\section{DISCUSSION}

The first phase of this research, eliciting the IPT, highlighted the need for systems thinking when researching community health committees due to their multilevel functioning. Operating in such open systems, CHCs are most likely strongly influenced by contextual factors ${ }^{20}$ and subject to human experiences. Specifically, committees cannot be managed or understood as a single entity, but as a group consisting of autonomous beings working towards a common goal. Theories applied to committees therefore most likely need to encompass perspectives from individuals, committees and the community in which the groups are initiated. They therefore require a methodology that is reflective of this by allowing for multiple theories, which aim to identify the most plausible explanatory framework for committee functioning. A realist evaluation (RE) is particularly apt to the study of community health committee interventions as both REs and CHC interventions share concepts regarding the importance of contexts, socioecological models and the assumption that programmes are open systems. There is also harmonisation between the methodology and elicited theories, including CCAT.

However, few realist evaluations have been conducted in a low-income country context ${ }^{23-30}$ and the authors are cautious of methodological issues that may arise. Notably, as experienced during IPT development, limited reports and literature document the context or contextual influences in which a programme operates, and though the researcher is to complete additional searches to highlight such concepts, contextual information may be missing or overlooked. Attempting to understand context from participants has also been a challenge, as 'contexts' within peoples' everyday environments may seem insignificant or not be recognised. Despite these foreseeable challenges, the research team is still of the opinion that the proposed benefits of conducting a realist evaluation and providing important programme-specific insight and explanations warrant continuing the protocol to data collection stages.

\section{CONCLUSIONS}

Though heavily advocated for and used in health projects across sub-Saharan Africa, there is little understanding of how CHCs function to contribute to programme objectives of capacity building. Moreover, while some evidence exists for the efficacy of CHCs in high-income contexts, rarely are CHCs studied in low-income contexts. With a dearth of evidence and understanding towards these groups, innovative methods are required to ascertain answers to the questions posed. Thus far, the methodology of a realist evaluation has been found suitable to address such questions. Within the field of operations research and implementation science, this research aims to provide contextually relevant and programmatic explanations for how health committees can contribute to capacity building for maternal and child health.

\section{Author affiliations}

${ }^{1}$ Centre for Global Health, Trinity College Dublin, Dublin, Ireland

${ }^{2}$ School of Nursing, Midwifery and Health Systems, University College Dublin, Dublin, Ireland

${ }^{3}$ World Vision Ireland, Dublin, Ireland

${ }^{4}$ World Vision International, Washington, District of Columbia, USA

${ }^{5}$ Health Systems Management, Ifakara Health Institute, Dar es Salaam, Tanzania

${ }^{6}$ Department of Epidemiology and Biostatistics, School of Public Health, Makerere University College of Health Sciences, Kampala Uganda

${ }^{7}$ School of Psychology, Trinity College Dublin, Dublin, Ireland

Twitter Follow Magnus Conteh at @XuberancelE

Acknowledgements The authors would like to thank World Vision Ireland and World Vision International for their commitment to this work as well as Irish Aid and the people of Ireland for their support of the AIM-Health project. The authors would also like to thank World Vision National Offices in Tanzania and Uganda for supporting this research and for providing essential insight into the context and programmes.

Contributors $B G$ developed the research protocol and prepared the first draft of the manuscript. FV, FL, EM, MC, ND, MG, HM and NT provide instrumental feedback into the design of the protocol and contributed to manuscript revisions. All authors read and approved the final version of the manuscript.

Funding World Vision Ireland and World Vision National Offices in Uganda and Tanzania sponsored this research.

Competing interests None declared.

Patient consent Obtained.

Ethics approval Trinity College Dublin's Health Policy and Management/ Centre for Global Health Research Ethics Committee (HPM/CGH REC); Makerere University School of Public Health (MakSPH); Uganda National Council for Science and Technology (UNCST); Ifakara Health Institute (IHI); Tanzania's National Medical Research Council (NIMR); Tanzanian Commission for Science and Technology (COSTECH).

Provenance and peer review Not commissioned; externally peer reviewed.

Open Access This is an Open Access article distributed in accordance with the Creative Commons Attribution Non Commercial (CC BY-NC 4.0) license, which permits others to distribute, remix, adapt, build upon this work noncommercially, and license their derivative works on different terms, provided the original work is properly cited and the use is non-commercial. See: http:// creativecommons.org/licenses/by-nc/4.0/

\section{REFERENCES}

1. World Health Organization, Health and Welfare Canada, Association $\mathrm{CPH}$. Ottawa Charter for Health Promotion: Charte DOttawa pour la Promotion de la Sante. In: International Conference on Health Promotion: the move towards a new public health. November 17-21, 1986. Ottawa, Canada, 1986.

2. WHO. Strengthening the performance of community health workers in primary healthcare. Report of a WHO Study Group. In: WHO Technical Report Series, No 780. Geneva: Edited by Organization $\mathrm{WH}, 1989$.

3. Feighery E, Rogers T. Building and Maintaining Effective Coalitions. Palo Alto, CA: Health Promotion Resource Center, Stanford Center for Research in Disease Prevention, 1990.

4. Zakocs RC, Edwards EM. What explains community coalition effectiveness: a reivew of the literature. Am J Prev Med 2006;3:351-61.

5. Butterfoss FD, Kegler MC. Towards a comprehensive understanding of community coalitions: moving from practice to theory. In: DiClemente RJ, Crosby RA, Kegler MC. Emerging theories in health promotion practice and research: strategies for improving public health. edn. San Francisco, CA: Jossey-Bass, 2002:157-93. 
6. Butterfoss FD, Goodman RM, Wandersman A. Community coalitions for prevention and health promotion. Health Educ Res 1993;8:315-30.

7. Labonte R, Laverack G. Capacity building in health promotion, Part 2: whose use? And with what measurement?. Critical Public Health 2001;11:129-38.

8. Naimoli J, Frymus D, Quain E, et al. Community and formal health system support for enhanced community health worker performance. USAID, 2012

9. Underwood C, Boulay M, Snetro-Plewman G, et al. Community capacity as means to improved health practices and an end in itself: evidence from a multi-stage study. Int Q Community Health Educ 2012;33:105-27.

10. Shrestha R. Using a community health system to strengthen the performance of village health committee. Presented at: CORE Group Conference 2014. 16-17 October 2014.

11. Granner ML, Sharpe PA. Evaluating community coalition characteristics and functioning: a summary of measurement tools. Health Educ Res 2004;19:514-32.

12. Brazier E, Fiorentino R, Barry MS, et al. The value of building health promotion capacities within communities: evidence from a maternal health intervention in Guinea. Health Policy Plan 2015;30:885-94.

13. Butterfoss FD. Coalitions and partnerships in community health San Francisco, CA: Jossey-Bass, 2007

14. Gray B, Wood DJ. Collaborative alliances: moving from practice to theory. J Appl Behav Sci 1991;27(1):3-22.

15. Craig $P$, Dieppe $P$, Macintyre $S$, et al. Developing and evaluating complex interventions: the new Medical Research Council guidance. BMJ 2008;337:a1655.

16. Dooris M, Poland B, Kolbe L, et al. Healthy settings: building evidence for the effectiveness of whole system health promotionchallenges and future directions. In: McQueen DV, Jones CM. Global perspectives on health promotion effectiveness. edn. New York, NY: Springer, 2007:327-52.

17. Kazi MAF. Realist evaluation for practice. Br J Soc Work 2003;33:803-18

18. Michie S, Abraham C. Interventions to change health behaviours: evidence-based or evidence-inspired? Psychol Health 2004;19:29-49.

19. Paterson C, Baarts C, Launsø L, et al. Evaluating complex health interventions: a critical analysis of the outcomes' concept. BMC Complement Altern Med 2009;9:18.

20. George A, Scott K, Garimella S, et al. Anchoring contextual analysis in health policy and systems research: a narrative review of contextual factors influencing health committees in low and middle income countries. Soc Sci Med 2015;133:159-67.

21. Byng R. Using realistic evaluation to evaluate a practice-level intervention to improve primary healthcare for patients with long-term mental illness. Evaluation 2005;11:69-93.

22. Marchal $\mathrm{B}$, van Belle $\mathrm{S}$, van Olmen $\mathrm{J}$, et al. Is realist evaluation keeping its promise? A review of published empirical studies in the field of health systems research. Evaluation 2012;18:192-212.

23. Ranmuthugala G, Cunningham FC, Plumb JJ, et al. A realist evaluation of the role of communities of practice in changing healthcare practice. Implement Sci 2011;6:49.

24. Maluka S, Kamuzora P, Sansebastian M, et al. Implementing accountability for reasonableness framework at district level in Tanzania: a realist evaluation. Implement Sci 2011;6:11.

25. Marchal B, Dedzo M, Kegels G. Turning around an ailing district hospital: a realist evaluation of strategic changes at Ho Municipal Hospital (Ghana). BMC public health 2010;10:787.

26. Dieleman M, Gerretsen B, van der Wilt GJ. Human resource management interventions to improve health workers' performance in low and middle income countries: a realist review. Health Res Policy Syst 2009;7:7.

27. Goicolea I, Coe AB, Hurtig AK, et al. Mechanisms for achieving adolescent-friendly services in Ecuador: a realist evaluation approach. Glob Health Action 2012;5. doi:10.3402/gha.v5i0.18748

28. Van Belle SB, Marchal B, Dubourg D, et al. How to develop a theory-driven evaluation design? Lessons learnt from an adolescent sexual and reproductive health programme in West Africa. BMC public health 2010;10:741.

29. Prashanth NS, Marchal B, Devadasan N, et al. Advancing the application of systems thinking in health: a realist evaluation of a capacity building programme for district managers in Tumkur, India. Health Res Policy Syst 2014:12:42.

30. Prashanth NS, Marchal B, Hoeree T, et al. How does capacity building of health managers work? A realist evaluation study protocol. BMJ Open 2012;2:e000882.
31. Pawson R, Tilley N. Realistic evaluation. London: Sage, 1997.

32. Merton RK. Social theory and social structure. New York: The Free Press, 1968

33. Bhutta ZA, Ahmed T, Black RE, et al. What works? Interventions for maternal and child undernutrition and survival. Lancet 2008;371:417-40.

34. Campbell OMR, Graham WJ. Strategies for reducing maternal mortality: getting on with what works. Lancet 2006;368:1284-99.

35. Jones G, Steketee RW, Black RE, et al. How many child deaths can we prevent this year? Lancet 2003;362:65-71.

36. World Vision. COMM Project Model: description and guidance for design. Washington, DC: World Vision Global Centre, 2014

37. Kabale District Local Government. Kabale District Local Government Statistical Abstract. Kabale: Uganda Bureau of Statistics, 2012.

38. Lwelamira J, Safari J. Choice of place for childbirth: prevalence and determinants of health facility among women in Bahi District, central Tanzania. Asian J Med Sci 2012;4:105-12.

39. United Republic of Tanzania. Population distribution by age and sex. Dar es Salaam: National Bureau of Statistics, Ministry of Finance, 2013.

40. Gilchrist VJ, Williams RE. Key informant interviews. In: Crabtree BF, Miller WL. Doing qualitative research $2 n d$ edn. Thousand Oaks, California: Sage Publications, 1999:71-88.

41. Yeo A, Legard R, Keegan J, et al. In-Depth Interviews. In: Ritchie J, Lewis J, McNaughton Nicholls C, Ormston R. Qualitative research practice: a guide for social science students \& researchers. 2nd edn. London, UK: SAGE Publications, 2014:177-210.

42. Sofaer S. Qualitative methods: what are they and why use them? Health Serv Res 1999;34:1101-18.

43. Kenney E, Sofaer S. Coalition self-assessment survey. NY, USA School of Public Affairs, Baruch College, City University of New York, 2002.

44. Sofaer S. Working together, moving ahead: a manual to support effective community health coalitions. New York: School of Public Affairs, Baruch College, 2000.

45. Kegler MC, Swan DW. An initial attempt at operationalizing and testing the Community Coalition Action Theory. Health Educ Behav 2011;38:261-70.

46. Kegler MC, Rigler J, Honeycutt S. How does community context influence coalitions in the formation stage? A multiple case study based on the Community Coalition Action Theory. BMC public health 2010;10:90.

47. Smith L. Community coalition action theory and its role in drug and alcohol abuse interventions. J Alcohol Drug Educ 2011;55:3-7.

48. Kiger PG, Butterfoss FD. Staying focused and moving forward: evaluation of a state cancer coalition. Poster presentation for the American Public Health Association. November. Philadelphia, PA. 2009.

49. Butterfoss FD, Gilmore LA, Krieger JW, et al. From formation to action: how allies against asthma coalitions are getting the job done. Health Promot Pract 2006;7(2 suppl):34S-43S.

50. Sandoval JA, Lucero J, Oetzel J, et al. Process and outcome constructs for evaluating community-based participatory research projects: a matrix of existing measures. Health Educ Res 2012;27:680-90.

51. Laverack G. Addressing the contradiction between discourse and practice in health promotion. Melbourne, Australia: Deakin University, 1999

52. Laverack G. Evaluating community capacity: visual representation and interpretation. Community Dev J 2006;41:266-76.

53. Manzano A. The craft of interviewing in realist evaluation. Evaluation 2016;22:342-60.

54. Westhorp G. Development of realist evaluation models and methods for use in small-scale community based settings. Nottingham, UK: Nottingham Trent University, 2008.

55. Salter KL, Kothari A. Using realist evaluation to open the black box of knowledge translation: a state-of-the-art review. Implement $S_{C i}$ 2014;9:115

56. Moore GF, Moore L, Murphy S. Integration of motivational interviewing into practice in the national exercise referral scheme in Wales: a mixed methods study. Behav Cogn Psychother 2012;40:313-30.

57. Uganda Bureau of Statistics. and ICF. Uganda demographic and health survey 2011. Kampala and Claverton: Uganda Bureau of Statistics and ICF International Inc, 2012.

58. National Bureau of Statistics (NBS) [Tanzania] and ICF Macro. Tanzania Demographic and Health Survey 2010. Dar es Salaam: National Bureau of Statistics (NBS) [Tanzania] and ICF Macro, 2011. 